\title{
Cultural Participation, Personality and Educational Inequalities
}

\author{
by Till Kaiser and Christian Schneickert \\ WZB Berlin Social Science Center; Otto-von-Guericke- University Magdeburg
}

\author{
Sociological Research Online, 21 (3), 14 \\ <http://www.socresonline.org.uk/21/3/14.html> \\ DOI: $10.5153 /$ sro.4063
}

Received: 11 Feb 2016 I Accepted: 16 Aug 2016 I Published: 31 Aug 2016

\begin{abstract}
Various studies have examined the relevance of either cultural capital or personality traits for academic achievement. Integrating these two fields of research, this study compares cultural participation in 'highbrow activities' and personality and their possible impact on the intergenerational transmission of educational inequalities in primary school. It also examines whether cultural participation in 'highbrow activities' and personality substitute for a non-academic background. The differences and similarities of the sociological concept of habitus and the psychological concept of personality are discussed on a conceptual level. Data are drawn from the German SocioEconomic Panel Study (SOEP) and the Families in Germany Study (FiD). Results show that the effect of parental education on school grades is partially mediated by three personality facets - Focus, Intellect, and Curiosity - as well as the cultural activity of playing music. Furthermore, the effect of parental education on school grades is multiple-mediated via playing music and Focus, as well as Curiosity to a small extent. Results of a multiple group analysis between children from academic and non-academic households show that participation in cultural activities and personality does not substitute for parental education.
\end{abstract}

Keywords: Cultural Capital, Cultural Participation, Personality, Habitus, Educational Inequalities, Primary School

\section{Introduction}

In educational sociology the construct of cultural capital is a dominant mechanism for explaining the reproduction of educational inequalities, although its measurement and relevance are still controversially discussed (e.g., Lareau \& Weininger 2003; Goldthorpe 2007; Edgerton \& Roberts 2014; Sullivan 2001, 2002 , 2007; Bennett et al. 2009; Bennett \& Silva 2011). Apart from this line of research, psychological studies showed in the last two decades that personality traits play an important role in predicting an individual's academic achievement across the life course (e.g. De Raad \& Schouwenburg 1996; Furnham et al. 2002; Borghans et al. 2008). In personality psychology 'traits of personality' are defined as 'the relatively enduring patterns of thoughts, feelings, and behaviors that reflect the tendency to respond in certain ways under certain circumstances' (Roberts 2009: 7). In this study, personality consists of the Big Five personality traits: Openness to Experience, Conscientiousness, Extraversion, Agreeableness, and Neuroticism/Emotional stability (see McCrae \& Costa 1987). The similarities to the sociological concepts of habitus and embodied cultural capital are striking. Bourdieu defines habitus as 'schemes of perception, thought and action' (1990: 54) as well as 'systems of durable, transposable dispositions' (1990: 53). Habitus coordinates the investment of economic, social, and cultural capital within the various environments of social fields (Bourdieu 1990: 66, 1984: 101; Bourdieu \& Wacquant 1992: 105106).

However, these two lines of research almost did not converge (as an exception, see Hart 2009). In the following we show that habitus and personality are very similar concepts, but that there are good reasons to use the validated concepts of personality traits and facets for an empirical operationalization (for other examples of empirical operationalization of habitus, see Stahl 2013; Watkins \& Noble 2013). Therefore the aim of this study is to integrate children's cultural capital and personality in one conceptual model. This offers us the opportunity to examine the extent to which they are related to each other and to help explain the intergenerational transmission of educational inequalities. To examine the impact of family background on children's personality development and educational success this study focuses on children in primary school, where the impact of family background 
on child development and educational success is more apparent than in later life. This study also adds to previous research by examining to what extent cultural capital and personality traits may substitute for a nonacademic background and may be a form of capital that could lead to educational upward mobility.

\section{Theoretical Considerations}

2.1 Various studies have demonstrated that personality traits are related to academic achievement, although some traits are highly relevant and others not (e.g., De Raad \& Schouwenburg 1996; Poropat 2009). A longitudinal study by Asendorpf and Van Aken (2003) showed that Conscientiousness [1] and Openness to Experience[2] are highly correlated with academic outcomes in primary school, whereas the other traits only played a minor role. An international meta-analysis also showed strong associations between these traits and academic achievement (Poropat 2009).

But why are these traits important when it comes to school grades? Openness to Experience is related to being intelligent, resourceful, and foresighted, and Conscientiousness is associated with focusing on homework, sustained effort, and goal setting, as well as learning-related time management and effort regulation (Barrick et al. 1993; Trautwein et al. 2006; Bidjerano \& Dai 2007; Poropat 2009). Therefore the two traits cover a set of dispositions that are highly relevant for success in school and are seen as competencies that are valuable and could be fostered to increase a child's success in school (Poropat 2009).

But why should Conscientiousness and Openness to Experience explain the correlation between social origin and children's success in primary school? While on the level of traits this is difficult to grasp, it becomes clearer when examining them on the level of facets. The trait level represents a highly aggregated global construct of personality. Below this level, traits consist of several distinguishable facets. For instance the personality trait Conscientiousness involves the facets Focus and Orderliness and the trait Openness to Experience the facets Intellect and Curiosity. Because facets are more specific than traits, they have been shown to be more precise predictors for different outcomes in specific contexts (MacCann et al. 2009; Roberts et al. 2012). For the trait Conscientiousness, it is important to distinguish different facets when it comes to academic achievement. In this study Conscientiousness is measured via the facets Focus and Orderliness. Previous research showed that Focus is relevant for success in school, whereas Orderliness is not (MacCann et al. 2009). Examining Conscientiousness on the trait level could therefore cause its effect to be underestimated. Similar problems could also be true for the facets of Openness to Experience (in this study: Intellect and Curiosity). Facets are also easier to connect to existing sociological research on social stratification: With regard to the occupational hierarchy, Focus and Intellect, and to some extent Curiosity as well, should be important for jobs that require high levels of skill, whereas Orderliness should be more relevant for routine tasks in production. Since 'facets of personality' are empirically well validated (e.g. Costa \& McCrae 1995) they can easily be operationalized for quantitative research, which is an advantage over the concept of habitus. The latter is a very broad theoretical concept. Although Bourdieu used extensive survey data in Distinction (Bourdieu 1984) to grasp the different forms of capital and lifestyles, he did not elaborate a specific methodology of habitus analysis and overall a qualitative and explorative approach is suggested. Therefore, the clear cut and quantitative operationalization of personality fits better for the objective of the paper at hand. Nevertheless, our measures of 'personality' can be understood as part of a broader habitus analysis. From our perspective, the theoretically elaborated concept of habitus could profit from the empirical validity of personality measures, whereas the concept of personality might profit from a theoretical substantiation and back bonding to the structures of society (for a critical discussion of the structure-agency-dualism, see Bourdieu 1990). Regarding the intergenerational transmission of habitual dispositions this is especially relevant.

In this context, Kohn (1989) demonstrated that parents tend to pass on to their children values about work that are relevant to their own occupations. Therefore, it could be argued that parents with demanding jobs that require high skill levels pass on valuable facets of personality to their children. With regard to the educational system, it is obvious that Focus, Intellect, and Curiosity are important capital for success in school. Therefore, it could be the case that these facets are more intensively fostered in households with a higher educational level, accompanied by a greater amount of embodied cultural capital. Kaiser and Diewald (2014) found evidence in support of this suggestion, demonstrating that mothers with a higher educational level tended to use childcentred parenting practices which foster the development of the child's Focus (at age 5-6 years), whereas this was not true for Orderliness. Similar fostering effects could also be expected for the facets Intellect and Curiosity. It can thus be argued that these facets are stratified in their development and act as mediators between parental education and school grades.

2.5 Cultural capital, besides the other forms of capital, habitus, social space, and social fields, is a central concept of Bourdieu's sociological theory of cultural and social reproduction (Bourdieu 1977, 1984; Bourdieu \& Wacquant 1992). Social reproduction, the theory goes, is the result of class-specific access to the dominant culture that is legitimised by the educational system through symbolic violence (Bourdieu \& Passeron 1977). 
From this perspective, parents from higher classes pass on cultural capital, including habitual dispositions as embodied cultural capital, to their children, who convert it into educational credentials (for an analysis of how students actively convert their habitual dispositions into educational success or failure, see Bourdieu \& Passeron 1979). According to Bourdieu (1986: 243-48) cultural capital exists in three forms:embodied as habitual dispositions, objectified as cultural artefacts (e.g. paintings, books, musical instruments), andinstitutionalized (e.g. diplomas).

The empirical operationalization of cultural capital is discussed controversially and a variety of measurements can be found in the literature (for an overview, see Dumais 2006: 86). The concept is criticized for being too fuzzy (Lareau \& Weininger 2003), since proxies can be found from individual and parental educational attainment (for an overview, see Sullivan 2001; Bennett \& Silva 2011), to the number of books at home (Evans et al. 2010), educational years (van Hek \& Kraaykamp 2013), to 'qualitative counter-attacks', against the individualization and omnivore hypotheses (Atkinson 2010, 2011), and completely new forms such as 'emerging cultural capital' (Savage et al. 2013).

However, participation in cultural activities has been frequently used over time in empirical social research (Dumais 2006: 86-91; see also DiMaggio 1982; De Graaf et al. 2000). But measuring cultural capital just through cultural participation in highbrow activities would be far too narrow. Therefore we do not claim to measure cultural capital as a whole through cultural participation but only one important part of cultural capital. In the following we make a clear distinction between cultural capital and cultural participation in 'highbrow' activities as specific part of cultural capital.

2.8 But why should cultural participation in 'highbrow activities' lead to success in school? Two possible pathways are expected (see Sullivan 2001): A habitus-field explanation would assume that cultural participation sends status signals to gatekeepers and is therefore rewarded by teachers (see Farkas et al. 1990;Jæger 2011), because the capital of highbrow culture is fully recognized and valued predominantly in the cultural fields itself. On the other hand, cultural participation in 'highbrow' activities itself could foster skills that are relevant for school success and therefore indirectly lead to success in school.

2.9 For instance, evidence of the positive effect of cultural participation on personality traits that are relevant for success in school can be found in a recent study by Hille and Schupp (2015), who demonstrated that playing music positively influences school grades (in secondary school), as well as Conscientiousness and Openness to Experience. These suggestions can be combined with the personality constructs on the facet level: Cultural participation in extracurricular activities could lead to improvement in the ability to focus and to learn new things more quickly (Intellect), as well as to a greater degree of Curiosity. Thus, besides simply mediating the effect of parental education on school grades through cultural participation, there may also be a multiple mediation effect via cultural participation and the facets Focus, Intellect, and Curiosity.

2.10 This article also addresses the question of whether cultural participation and personality traits may substitute for a lack of parental education (cultural capital). In the literature on cultural capital, this phenomenon is referred to as 'cultural mobility' (DiMaggio 1982). A recent study also found this kind of upward mobility among children who were being trained in music (Hille \& Schupp 2015). In another recent report, Shanahan et al. (2014) showed that the rewards of valuable personality traits are higher for children whose parents are less well educated, whereas another recent study did not confirm the results (Damian et al. 2015). Nevertheless, the personality facets relevant for success in primary school, as well as cultural participation in 'highbrow' activities, might compensate the child for having parents with a lower educational level. For such children, the rewards should be even higher than for those whose parents have a higher educational level. For the latter, contact with highbrow culture is likely in many occasions of their everyday life, whereas for children from non-academic backgrounds extracurricular highbrow activities might be the only chance to get in touch with this world of legitimate culture (Bourdieu 1984).

\section{Hypotheses}

3.1 Based on the previous suggestions, the following hypotheses are proposed. Figure 1 displays the different hypotheses; the numbers 1 to 6 in parentheses correspond to the pathways of the mediation model, and numbers 7 and 8 correspond to the moderation model.

- Parental education positively influences children's school grades (1).

- The facets Focus (Conscientiousness), Intellect, and Curiosity (Openness to Experience) positively affect school grades (2).

- Focus (Conscientiousness), Intellect, and Curiosity (Openness to Experience)...

....are positively influenced by parental education (3).

....acts as transmission mechanisms between parental education and school grades $(3,2)$, 
- The cultural participation in the 'highbrow' activities playing music and dancing or acting...

....is positively affected by parental education (5).

...positively influences school grades (4).

... act as transmission mechanism between parental education and school grades $(5,4)$.

... positively influences Focus, Intellect, and Curiosity (6).

- The effect of parental education on school grades (1) is mediated in multiple ways through cultural participation and Focus, Intellect, and Curiosity $(5,6,2)$.

- Focus, Intellect, and Curiosity, (7), and cultural participation in 'highbrow' activities (8) substitute for a lack of parental education with regard to school grades.
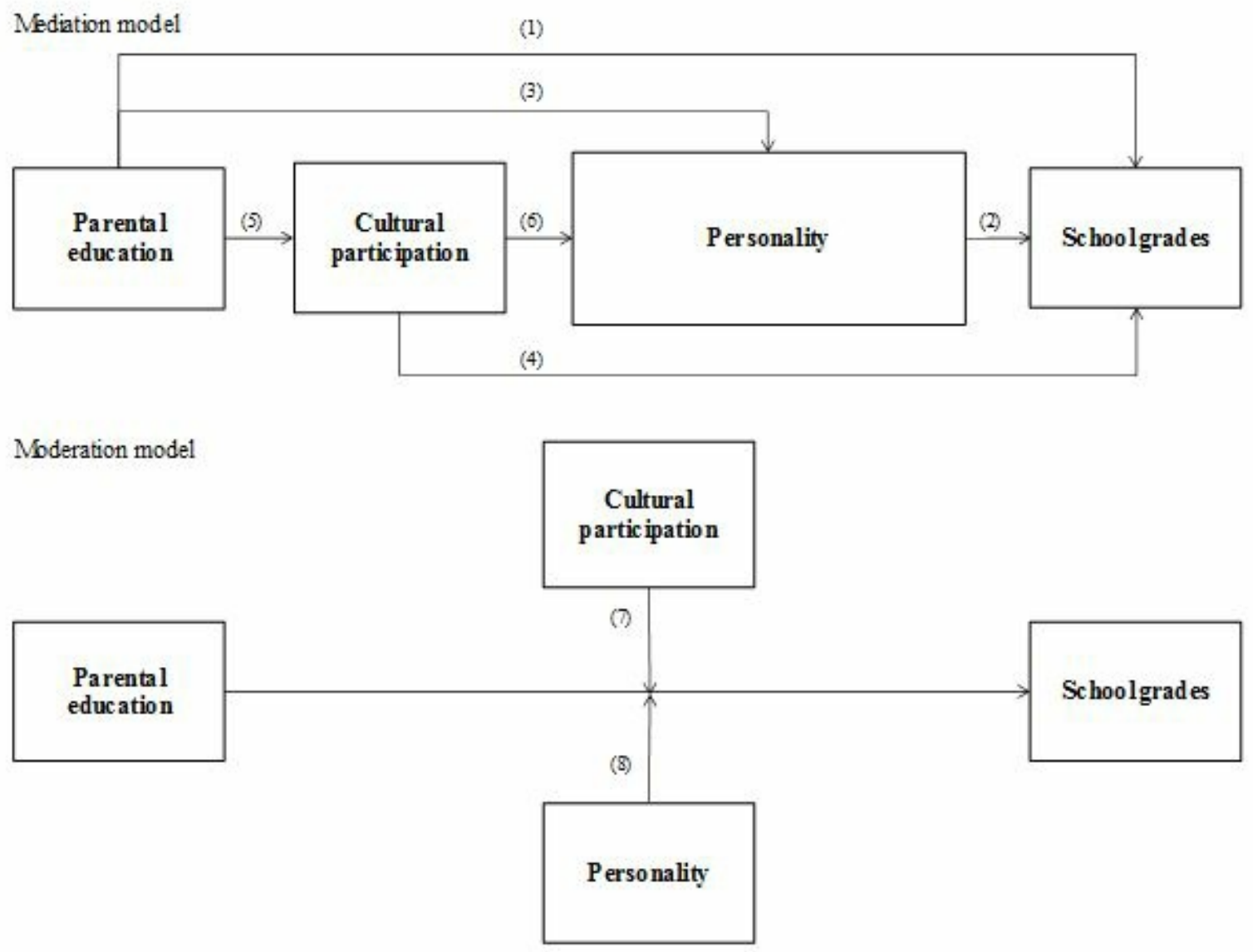

Figure 1. Proposed models

\section{Data}

4.1 For the analysis, data from the German Socio-Economic Panel Study (SOEP) and the SOEP enhancement Families in Germany (FiD) were used. The SOEP is a representative annual household panel study that started in 1984 and contains information on roughly 20,000 individuals living in 12,000 households in the most recent wave (see Wagner et al., 2007). The FiD is an enhancement of the SOEP that includes a subsample of lone mothers, low-income families and large families. The FiD contains information on about 4500 households with about 7500 respondents (see Schröder et al., 2013). The content and structure of the data sets are similar and can be analysed jointly. The calculations are based on a merged dataset of the SOEP wave 2012 and the FiD waves 2010-2013, resulting in a cross-sectional dataset that contains information on children between the ages of 9 and 10 years and information about their mothers or fathers and the household[3] $(\mathrm{N}=1,668)$. For a description of the variables (means, standard deviation, range, and scale), see Table A1 and for a correlation matrix, Table A2.

\section{Measures}

5.1 The personality of the children is measured by a short instrument of the Five Factor Questionnaire for Children (FFK-K) that was developed and validated for the SOEP (Weinert et al. 2007). It is based on the original Five Factor Questionnaire for Children that was validated through a German nine-year longitudinal study using ratings of teachers, friends and parents of the children (see Asendorpf \& Van Aken 2003). Each of the five traits is measured via two facets. The facets are measured via one Item. Parents were asked to rank their children on a scale of 0 to 10 for each item, as compared with the child's peers (see Table 1). The facet Focus was measured as ranging from 'focused' to 'easily to distracted', the facet Intellect was measured as ranging from 'understands quickly' to 'needs more time', and the facet Curiosity was measured as ranging from 'not that 
interested' to 'hungry for knowledge'. The scales for the first two of these facets were then reversed for a more intuitive interpretation.

Table 1. Personality traits with factor loadings

\begin{tabular}{|c|c|c|}
\hline Personality Trait & Facets & $\begin{array}{l}\text { Std. } \\
\text { Factor } \\
\text { Loadings }\end{array}$ \\
\hline & \multicolumn{2}{|c|}{ How would you rank your child in comparison to other children of the same age? Child ... } \\
\hline \multirow[t]{2}{*}{ Openness } & understands quickly ... needs more time* & 0.58 \\
\hline & is not that interested ... hungry for knowledge & 0.71 \\
\hline \multirow[t]{2}{*}{ Conscientiousness } & is unorderly ... orderly & 0.35 \\
\hline & is Focused ... easy to distract* & 0.85 \\
\hline \multirow[t]{2}{*}{ Extraversion } & is withdrawn ... sociable & 0.74 \\
\hline & is talkative ... quiet* & 0.60 \\
\hline \multirow[t]{2}{*}{ Agreeableness } & is obstinate ... compliant & 0.59 \\
\hline & is good natured ... irritable* & 0.62 \\
\hline Neuroticism/ & is self confident ... insecure ${ }^{*}$ & 0.80 \\
\hline Emotional Stability & is fearful ... fearless & 0.54 \\
\hline
\end{tabular}

Notes: The scale ranged from 0 to $10 ;{ }^{*}$ indicates that the scale was inverted. $N=1,668$. Model fit of the SCFA:

$\mathrm{X}^{2}=118.790, \mathrm{df}=20, \mathrm{p}<0.001, \mathrm{CLI}=0.96, \mathrm{TLI}=0.01, \mathrm{RMSEA}=0.054, \mathrm{SRMR}=0.029$. The complete model, including unstandardised results and residual covariances/correlations, is available from the author.

5.2 To test the instrument on its (internal) validity, a simultaneous confirmatory factor analysis (SCFA) was estimated. Results showed that the factor loadings were of sufficient size except for the factor Conscientiousness (see Table 1). This was not surprising because studies from psychology showed a lot of heterogeneity within this construct (see Roberts et al. 2012). To test the measurement invariance of this instrument among parents with an academic or a non-academic background, a multiple group analysis was estimated, that established measurement invariance (see Results).

5.3 The school grades of each child were measured on a scale of 1 to 6 , and the scale was then reversed for a more intuitive interpretation (with a higher value reflecting a better grade). Which primary school the children attend is not as socially stratified as in other countries because the selection depends on the district in which the parents live; moreover, private schools play almost no role in Germany.

5.4 Cultural participation was measured by asking the parents how often their child 'played music' or 'danced or acted or did something similar'. For this assessment, a five-point Likert scale was used, with the following choices: (1) daily, (2) every week, (3) every month, (4) less frequently, or (5) never. The scale was then reversed for a more intuitive interpretation.

5.5 Parental education $\left.{ }^{4}\right]$ was measured according to the highest level of schooling in the household. The results were controlled for the sex of the child and the parent, the parent's age, employment status $(0=$ Not Employed, 1=Part Time, 2=Full Time), and marital status (1=Married, 2= Single/widowed, 3=Divorced), and a dummy for the different studies (SOEP/FiD) was added to the model. To control for any additional unobserved stable household characteristics, sibling fixed-effects models were estimated as robustness checks (see Sensitivity Analysis).

\section{Methods}

6.1 A structural equation (SE) model was estimated. Through the simultaneous estimation of the structural equation, one can easily distinguish direct and indirect effects to test the mediational hypotheses. Resource substitution hypotheses were tested by estimating a multiple group analysis that distinguished between children with and without an academic background. This provided an opportunity to test the moderating effects by comparing the relevant path coefficients and to test whether they differed significantly between the groups by comparing nested models. Another important issue addressed this way was measurement invariance across groups. To ensure that the instrument would measure the same for children with or without academic background, the Big Five traits were tested for measurement invariance across groups, an important issue that is often overlooked. Because the data were partly non-normally distributed, a robust maximum-likelihood estimator (MLR) was used. To check the robustness of the results, additional analyses were carried out, including siblings fixed-effects models and bootstrapping with bias-corrected confidence intervals. 


\section{Results}

7.1 The direct effects within the estimated SE model (Table 2) show the postulated effects of Focus, Intellect, Curiosity, and playing music on school grades, with the effects of personality being much greater than the effect of playing music. It is also apparent that the effects of Intellect and Focus are greater than the effect of Curiosity. This is not surprising because these facets are more related to intelligence than is Curiosity, which is highly predictive of school grades (see Poropat 2009). This analysis could not control for intelligence, but previous studies that took both intelligence and personality into account still found substantial robust significant correlations among Openness to Experience, Conscientiousness, and school success. Therefore, these correlations should be smaller but substantial (see also Asendorpf \& Van Aken 2003; Poropat 2009). The positive effect of playing music was also noted in previous studies (e.g. Hille \& Schupp 2015). The results also show that parental education has a significant and substantial direct effect on German and Mathematics. Thus, it is clear that the effect of parental education on school grades is not fully mediated through personality and cultural participation.

7.2 On examining the social stratification of personality, it becomes obvious that Focus, Intellect, Curiosity, and cultural participation are, as expected, significantly and substantively positively correlated with parental education, whereas Orderliness is weakly negatively related to parental education. The correlation between cultural participation in 'highbrow' activities and parental education is positive and substantial. Because inspecting the direct effects does not reveal anything about the mediational role of the constructs, the next step was to examine to what extent personality and cultural participation act as transmission mechanisms between social origin and school grades. The largest mediation effects were found for Intellect and Focus, while Curiosity and playing music mediated the correlation between parental education and school grades to a smaller degree (Table 2a). For the 'highbrow' activity 'dancing or acting', no mediation effects occurred.

7.3 In summary, the facets of personality play a much larger role than cultural participation in 'highbrow' activities. Converted into Bourdieusian language, the dispositions of the habitus outperform a certain form of cultural capital. To be investigated further is the extent to which participation in 'highbrow' activities affects these facets, and whether multiple mediation takes place of the effect of parental education on school grades via cultural participation and facets of personality.

Table 2. Structural equation (SE) model 


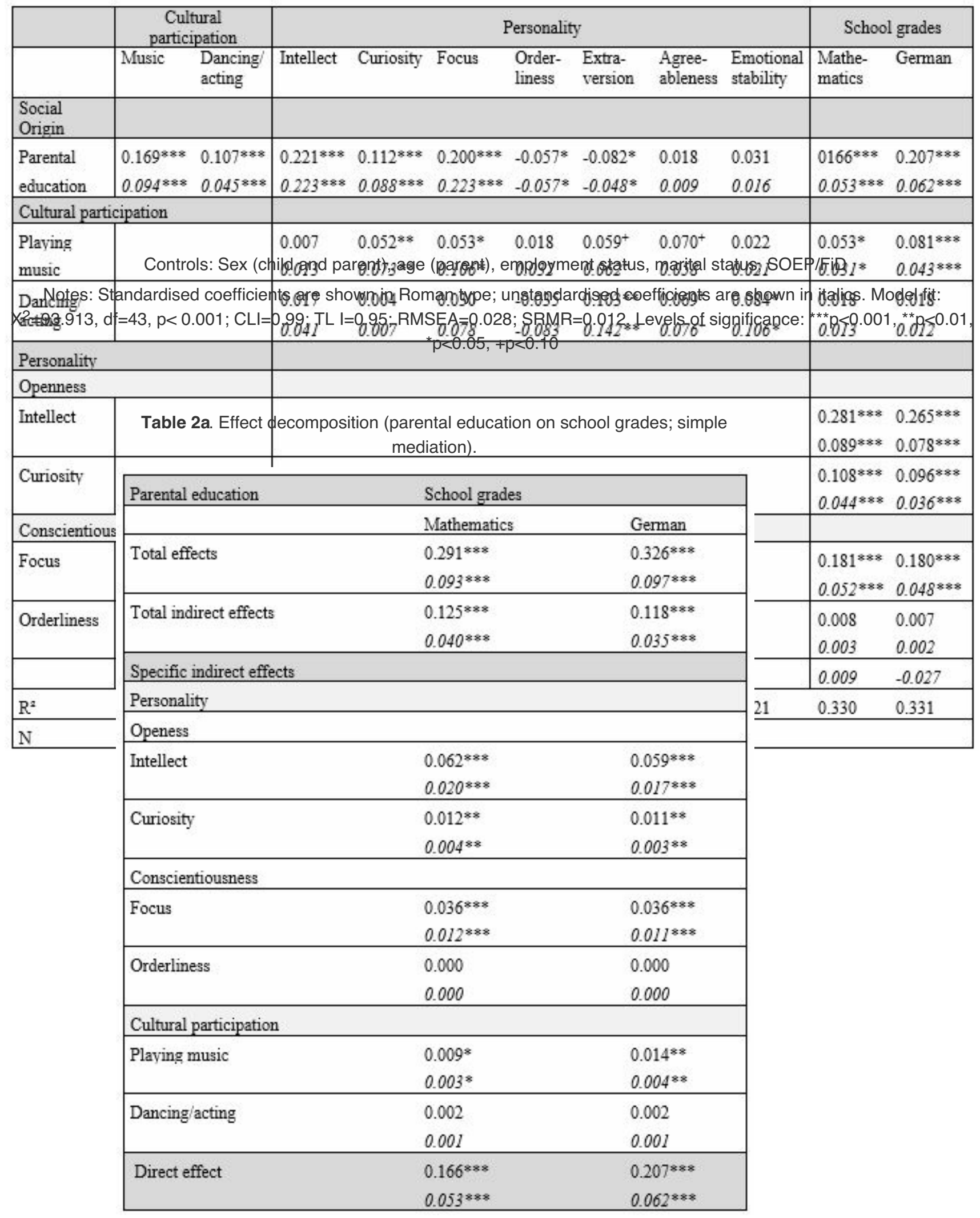


Results belong to the estimated SE model presented in Table 2.

7.4 Regarding the direct effects of cultural participation in 'highbrow' activities, it was observed that dancing or acting did not influence the facets of personality, while playing music had a weak effect on Focus and Curiosity (see Table 2). The effect of 'highbrow' activities on Mathematics was weakly mediated through Curiosity (see Table 2b). A multiple mediation of the effect of parental education on Mathematics through playing music, Focus, and Curiosity was observed, but this effect was very small and tended toward zero (see Table 2c).

Table 2b. Effect decomposition (playing music on school grades; simple mediation).

\begin{tabular}{|lll|}
\hline Playing music & School grades & \\
\hline Total effects & Mathematics & German \\
\hline Total indirect effects & $0.066^{* 8}$ & $0.095^{888}$ \\
& $0.038^{88}$ & $0.051^{888}$ \\
\hline Indirect effects & 0.012 & 0.014 \\
\hline Focus & 0.007 & 0.008 \\
& & \\
Intellect & $0.010^{*}$ & $0.010^{8}$ \\
& $0.006^{8}$ & $0.005^{8}$ \\
Curiosity & 0.002 & 0.002 \\
& $0.001^{8}$ & $0.001^{8}$ \\
\hline Direct effect & $0.006^{+}$ & $0.005^{+}$ \\
& $0.003^{-}$ & $0.003^{-}$ \\
\hline
\end{tabular}

Results belong to the estimated SE model presented in Table 2.

Table 2c. Effect decomposition (parental education on school grades; multiple mediation). 


\begin{tabular}{|c|c|c|}
\hline \multirow[t]{2}{*}{ Parental education } & \multicolumn{2}{|l|}{ School grades } \\
\hline & Mathematics & German \\
\hline \multirow{2}{*}{ Total effects } & $0.291^{888}$ & $0.326^{* 88}$ \\
\hline & $0.093^{* 8 * 8}$ & $0.097^{* * 8}$ \\
\hline \multirow[t]{2}{*}{ Total indirect effects } & $0.125^{* * *}$ & $0.118^{* * 8}$ \\
\hline & $0.040^{* 8 *}$ & $0.035^{* 88}$ \\
\hline \multicolumn{3}{|l|}{ Multiple indirect effects } \\
\hline \multirow[t]{2}{*}{ Via playing music and Focus } & $0.002^{+}$ & $0.002^{+}$ \\
\hline & $0.001^{-}$ & $0.000^{-}$ \\
\hline \multirow[t]{2}{*}{ Via playing music and Intellect } & 0.000 & 0.000 \\
\hline & 0.000 & 0.000 \\
\hline \multirow{2}{*}{ Via playing music and Curiosity } & $0.001^{+}$ & $0.001^{+}$ \\
\hline & $0.000^{-}$ & $0.000^{-}$ \\
\hline \multirow[t]{2}{*}{ Via dancing and acting and Focus } & 0.001 & 0.001 \\
\hline & 0.000 & 0.000 \\
\hline \multirow[t]{2}{*}{ Via dancing and acting and Intellect } & 0.001 & 0.000 \\
\hline & 0.000 & 0.000 \\
\hline \multirow[t]{2}{*}{ Via dancing and acting and Curiosity } & 0.000 & 0.000 \\
\hline & 0.000 & 0.000 \\
\hline \multicolumn{3}{|c|}{ 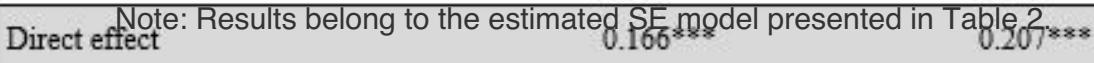 } \\
\hline & $0.053^{* 8 * 8}$ & $0.062^{888}$ \\
\hline
\end{tabular}

The effect of playing music on German was to a very small extent mediated through Curiosity (see

Table 2b). The effect of parental education on German is multiply mediated through playing music and Focus, as well as through playing music and Curiosity, but the effects sizes tended toward zero (see Table 2c). In summary, the influences of cultural participation in 'highbrow' activities on valuable facets of personality were small and weaker than suggested.

7.6 The possible substitution effects of personality and cultural participation were studied by estimating a multiple group analysis for the groups of children whose parents did or did not have an academic background (see Table 2). In a group comparison, results will be valid if the measurement models are invariant across the groups. Therefore, as a first step, the latent variables (including Conscientiousness and Openness to Experience on the trait level) were tested for metric measurement invariance by comparing nested models with the SatorraBentler chi-square test, and measurement invariance was established.[5] In the next step, the multiple group analysis was estimated (see Table 2). Only the unstandardized coefficients should be compared between groups because the standardised ones are influenced by the size of the group.

7.7 Comparing the effects of personality between the groups showed that the effects of Focus, Intellect, and Curiosity on German were slightly stronger for the group whose parents did not have an academic background. For children whose parents did have an academic background, Curiosity had a positive and significant effect on Mathematics, but this was not true for the non-academic group. Intellect and Focus were slightly more strongly related to Mathematics in the group with an academic background. Thus, the results were not consistent. With regard to cultural participation, for the non-academic group, playing music as well as dancing and acting were positively related to school grades, while for the academic group, the effect of playing music was significant only on German. However, testing the effects of personality and cultural participation with respect to their differences indicated that the group differences were not significant.[6] Thus, personality and cultural participation in 'highbrow' activities did not substitute for a lack of parental education with regard to school grades. From a Bourdieusian perspective this is plausible: parental education and personality (as part of the habitus) show strong inertia effects that cannot be disengaged in the short-run by simply participating in highbrow cultural activities (Bourdieu 1984).

Table 3. Multiple group analysis (model with freely estimated path coefficients). 


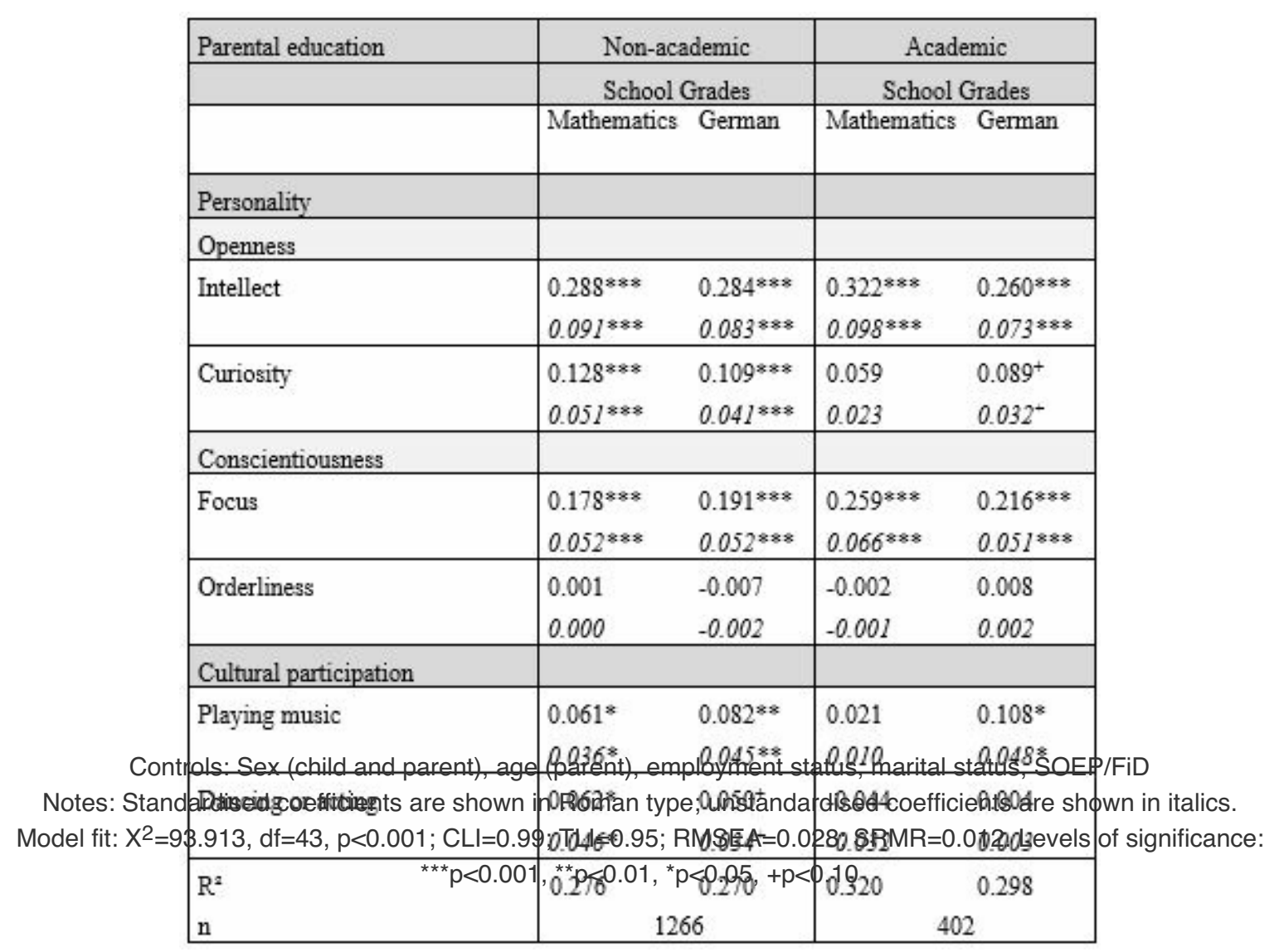

7.8 Because variables may have been omitted, sibling fixed-effect models were estimated (see supplementary material, online) $(n=353 ; N=173)$, which should account for unobservable stable household characteristics. Results confirmed the importance of Intellect and Focus for school success, whereas the effects of playing music and Curiosity were not significant. Given the small sample size, these results should be treated with caution. In addition to testing the indirect effects on the robustness of the results, bootstrapping with biascorrected confidence intervals was used, which confirmed the results presented. Furthermore, to check the presented SE model on its robustness, the model was re-estimated using the full information maximum likelihood (FIML) estimator (covariance coverage $>0.90$ ), which confirmed the results.

\section{Discussion}

8.1 This study integrates for the first time constructs of personality psychology and research on cultural capital into one model to examine to what extent cultural participation in 'highbrow' activities and personality (in particular the traits Conscientiousness and Openness to Experience) are related to each other, if they act as intergenerational transmission mechanisms of educational inequalities, and/or substitute for a lack of parental education with regard to school success. Additionally, it was important to consider personality on the level of facets and not on the level of traits, because transmission processes could otherwise be obscured.

8.2 The results showed that the participation in the 'highbrow' activity of playing music and the facets Focus (Conscientiousness), Intellect, and Curiosity (Openness to Experience) were relevant for success in primary school, whereas acting and dancing and the facet Orderliness (Conscientiousness) did not play a role. Regarding the large effect of parental education on children's school grades, personality and cultural participation did not fully mediated this effect, but they mediated about one third of the effect - a substantial amount. So combining cultural participation and personality helps to increase the explanation of the well-known correlation between the education of the parents and of the child. Cultural participation was only weakly correlated to Conscientiousness and Openness to Experience. Since we suggested that cultural participation may partly explain the correlation between these personality traits and parental education we were surprised by this finding. But of course it could be the case that other activities and child rearing practices may help to explain these correlations. These questions should be addressed in more detail in further studies. Since there was a weak correlation between cultural participation and Conscientiousness and between cultural participation and Openness to Experience it was not a surprise that the effect of cultural participation on school grades was only weakly mediated through personality. The tests for multiple mediation effects produced the same result: The effect of parental education on school grades was in part multiply mediated via playing music and the facets Focus and Curiosity, but the effect sizes tended toward zero. 

educational inequalities than cultural participation in 'highbrow' activities.

This point is striking, because much of previous research highlighted the relevance of cultural participation for the reproduction of educational inequalities (e.g. DiMaggio 1982: Farkas et al. 1990; Jæger, 2011). Our study shows that personality outperforms cultural participation in highbrow activities in explaining the reproduction of educational inequalities in primary school.

This study also demonstrated the importance of examining personality on the level of facets, which are more precise predictors of school grades: Examining Conscientiousness on the trait level would have obscured the effect of Focus on school grades because Orderliness is not related to success in school.

Clearly, this study was limited by the fact that only cross-sectional data could be used, and further longitudinal research is needed. Nevertheless, a number of recent studies using a longitudinal design have confirmed some of the suggestions made in this study, in that they found evidence for the stratified development of Conscientiousness (see Kaiser \& Diewald 2014), as well as for a small mediational role of valuable personality traits between social origin and success in the life course (see Shanahan et al. 2014). With our dataset we could also not address the question to what extent social networks are established and used through highbrow activities. This important question should be examined in future research.

In addition to the mediation hypotheses, this study examined the moderation of the effect of parental education on school grades through cultural participation in 'highbrow' activities, as well as through personality. The first results of the multiple group analysis provided a somewhat ambiguous picture, and the results of testing the path coefficients for differences across groups were not significant. Thus, these hypotheses could not be confirmed. Only two previous studies have tested the substitution hypotheses in regard to personality. Although one study found evidence for the substitution hypotheses (Shanahan et al. 2014), the other did not (Damian et al. 2014) - therefore still more research is needed to shed a light on this topic.

On a conceptual level, we briefly discussed the similarities between personality and habitus. Facets of personality are well validated constructs in psychological research leading us to put the focus on personality in the context of the empirical objective of the paper. Nevertheless we do believe both concepts would profit from a systematic synthesis and we hope to encourage future research in this field of interest to further elaborate on that. Therefore, combining the constructs of personality psychology and cultural capital showed that even if not explaining the whole correlation between parental cultural capital and child's school grades, about one third of the correlation could be explained by personality and cultural participation - a remarkable amount - showing that the integration of personality psychology and sociology is fruitful for the examination of intergenerational transmission processes of educational inequalities.

\section{Appendix 1}

Table A1. Means, Standard Deviations, Range and Scale. 


\begin{tabular}{|c|c|c|c|c|}
\hline Variables & Mean & SD & Range & Scale \\
\hline \multicolumn{5}{|l|}{ Child: } \\
\hline \multicolumn{4}{|l|}{ Schoolgrades: } & $1-6$ \\
\hline Mathematics & 4.60 & 0.89 & $2-6$ & \\
\hline German & 4.60 & 0.83 & $2-6$ & \\
\hline \multicolumn{4}{|l|}{ Openess } & $0-10$ \\
\hline Intellect & 7.00 & 2.82 & $0-10$ & \\
\hline Curiosity & 7.69 & 2.20 & $0-10$ & \\
\hline \multicolumn{4}{|c|}{ Conscientiousness } & $0-10$ \\
\hline Focus & 5.33 & 3.12 & $0-10$ & \\
\hline Orderliness & 4.78 & 2.80 & $0-10$ & \\
\hline \multicolumn{4}{|l|}{ Extraversion } & $0-10$ \\
\hline Talkative & 7.40 & 2.51 & $0-10$ & \\
\hline Outgoing & 7.69 & 2.20 & $0-10$ & \\
\hline \multicolumn{4}{|l|}{ Agreeableness } & $0-10$ \\
\hline Obedient & 5.79 & 2.51 & $0-10$ & \\
\hline Good natured & 7.06 & 2.63 & $0-10$ & \\
\hline \multicolumn{4}{|c|}{ Emotional Stability / Neuroticism } & $0-10$ \\
\hline Relaxed & 6.26 & 2.52 & $0-10$ & \\
\hline Self assured & 6.54 & 2.63 & $0-10$ & \\
\hline \multicolumn{4}{|c|}{ Cultural Participation } & $1-5$ \\
\hline Playing music & 2.86 & 1.56 & $1-5$ & \\
\hline Dancing/acting & 2.23 & 1.18 & $1-5$ & \\
\hline \multicolumn{5}{|c|}{ Sociodemographics } \\
\hline Age & 10.00 & 0.02 & $9-10$ & \\
\hline Sex & 0.51 & & $0-1$ & $\begin{array}{l}0=\text { Male }, \\
1=\text { Female }\end{array}$ \\
\hline
\end{tabular}

\begin{tabular}{|c|c|c|c|c|}
\hline \multicolumn{5}{|l|}{ Parent: } \\
\hline \multicolumn{5}{|l|}{ Sociodemographics } \\
\hline Age & 39.78 & 5.44 & $26-56$ & \\
\hline Sex & 0.95 & 0.21 & $0-1$ & $\begin{array}{c}0=\text { Male, } \\
1=\text { Female }\end{array}$ \\
\hline Employment Status & Percent & & & \\
\hline Not employed & 32.19 & & & 0 \\
\hline Part time & 51.32 & & & 1 \\
\hline Full time & 16.49 & & & 2 \\
\hline Marital Status & \multicolumn{3}{|c|}{ Note: $\mathrm{N}=1,668$} & \\
\hline Married & \multicolumn{2}{|l|}{66.49} & & 0 \\
\hline Single & \multicolumn{2}{|l|}{16.91} & & 1 \\
\hline Divorced & \multicolumn{3}{|c|}{ Table A26.8pearman's rank correlation coefficients. } & 2 \\
\hline
\end{tabular}

\begin{tabular}{llllllllll} 
& $(1)$ & $(2)$ & $(3)$ & $(4)$ & $(5)$ & $(6)$ & $(7)$ & $(8)$ & (9) \\
\hline (1) Mathematics & 1.000 & & & & & & & & \\
(2) German & 0.601 & 1.000 & & & & & & & \\
(3) Parental education & 0.325 & 0.350 & 1.000 & & & & & & \\
(4) Intellect (O) & 0.469 & 0.444 & 0.219 & 1.000 & & & & & \\
(5) Curiosity (O) & 0.301 & 0.279 & 0.139 & 0.486 & 1.000 & & & & \\
(6) Focus (C) & 0.381 & 0.410 & 0.225 & 0.476 & 0.272 & 1.000 & & & \\
(7) Orderliness (C) & 0.084 & 0.099 & -0.030 & 0.110 & 0.148 & 0.298 & 1.000 & & \\
(8) Playing music & 0.119 & 0.188 & 0.181 & 0.068 & 0.085 & 0.131 & 0.030 & 1.000 & \\
(9) Dancing/acting & 0.091 & 0.155 & 0.155 & 0.062 & 0.058 & 0.099 & -0.006 & 0.273 & 1.000 \\
\hline
\end{tabular}

Note: $N=1,668$. 


\section{Notes}

"Conscientiousness is a spectrum of constructs that describe individual differences in the propensity to be self-controlled, responsible to others, hardworking, orderly, and rule abiding." (Roberts et al. 2012: 1).

"High-O individuals are imaginative and sensitive to art and beauty and have a rich and complex emotional life; they are intellectually curious, behaviorally flexible, and nondogmatic in their attitudes and values" (Costa \& McCrae 1992: 6)

Data were drawn from the first parent interview. If during this interview the parent could not be identified as the biological parent, data were obtained, if possible, from the other parent (if he or she was the biological parent) in the second parent interview.

Unfortunately we did not have indicators to measure social capital. Economic capital is only weakly correlated to personality, cultural activities and school grades (for instance the correlations with school grades and playing music are below 0.05). Compared with the correlations of cultural capital these correlations are very weak (see Table A2).

Difference test between groups: $T R d=6.144, d f=5, p>0.05$. Fit of the models: Model with freely estimated factor loadings: $X^{2}=440.692, \mathrm{df}=60, \mathrm{p}<0.001 ; \mathrm{CLI}=0.85 ; \mathrm{TLI}=0.77 ; \mathrm{RMSEA}=0.087 ; \mathrm{SRMR}=0.058$. Model with equal factor loadings across groups: $\mathrm{X}^{2}=457.316, \mathrm{df}=55, \mathrm{p}<0.001 ; \mathrm{CLI}=0.84 ; \mathrm{TLI}=0.74 ; \mathrm{RMSEA}=0.094$; SRMR=0.055.

Difference test between groups: $T R d=12.6923, d f=12, p>0.05$. Fit of the models: Model with freely estimated path coefficients: $X^{2}=135.878, d f=80, p<0.001 ; C L I=0.99 ; T L I=0.94 ;$ RMSEA=0.029; SRMR=0.016. Model with equal path coefficients across groups: $X^{2}=148.150, d f=92, p<0.001 ; C L I=0.99 ; T L I=0.95$; RMSEA=0.027; SRMR=0.018.

\section{References}

ASENDORPF, J.B., and M.A.G. Van Aken. (2003). Validity of Big Five personality judgments in childhood: a 9 year longitudinal study. European Journal of Personality17, no. 1: p. 1-17. [doi:10.1002/per.460]

ATKINSON, W. (2010). Class, Individualisation and Perceived (Dis)advantages: Not Either/Or but Both/And? Sociological Research Online 15, no. 4. [doi:10.5153/sro.2214]

ATKINSON, W. (2011). The context and genesis of musical tastes: Omnivorousness debunked, Bourdieu buttressed. Poetics 39, no. 3: p. 169-86. [doi:10.1016/j.poetic.2011.03.002]

BARRICK, M.R., M.K. Mount, and J.P. Strauss. (1993). Conscientiousness and performance of sales representatives: Test of the mediating effects of goal setting. Journal of Applied Psychology78, no. 5: p. 715-22. [doi:10.1037/0021-9010.78.5.715]

BENNETT, T., M. Savage, E. Silva, A. Warde, M. Gayo-Cal, and D. Wright. (2009).Culture, Class, Distinction. London: Routledge.

BENNETT, T., and E. Silva. (2011). Introduction: Cultural capital-Histories, limits, prospects.Poetics 39, no. 6: 427-43. [doi:10.1016/j.poetic.2011.09.008]

BIDJERANO, T., and D.Y. Dai. 2007. The relationship between the big-five model of personality and selfregulated learning strategies. Learning and Individual Differences 17, no. 1: p. 69-81. [doi:10.1016/j.lindif.2007.02.001]

BORGHANS, L., Duckworth, A. L., Heckman, J. J., \& Ter Weel, B. (2008). The economics and psychology of personality traits. Journal of Human Resources 43, no. 4: p. 972-1059. [doi:10.3386/w13810] 
BOURDIEU, P. (1977). Cultural Reproduction and Social Reproduction. InPower and Ideology in Education ed. J. Karabel and A.H. Halsey, p. 487-510. New York, NY: Oxford University Press.

BOURDIEU, P. (1984). Distinction: A Social Critique of the Judgement of Taste London: Routledge.

BOURDIEU, P. (1986). The forms of capital. p. 241-58 InHandbook of Theory and Research for the Sociology of Education, ed. J. G. Richardson. New York: Greenwood.

BOURDIEU, P., and J.-C. Passeron. (1977). Reproduction in Education, Society and Culture London: Sage Publications.

BOURDIEU, P., and J.-C. Passeron. (1979). The Inheritors. French Students and their Relation to Culture Chicago: University of Chicago Press.

BOURDIEU, P. (1990). The Logic of Practice. Stanford and Cambridge: University Press and Polity Press.

BOURDIEU, P., and L. J. D. Wacquant. (1992). An invitation to reflexive sociology. Cambridge: Polity Press.

COSTA, P. T., \& McCrae, R. R. (1992). Normal personality assessment in clinical practice: The NEO Personality Inventory. Psychological assessment, 4, no. 1: p. 5. [doi:10.1037/1040-3590.4.1.5]

COSTA Jr, P. T., \& McCrae, R. R. (1995). Domains and facets: Hierarchical personality assessment using the Revised NEO Personality Inventory. Journal of personality assessment64, no. 1, p. 21-50. [doi:10.1207/s15327752jpa6401_2]

DAMIAN, R. I., Su, R., Shanahan, M., Trautwein, U., \& Roberts, B. W. (2015). Can personality traits and intelligence compensate for background disadvantage? Predicting status attainment in adulthood. Journal of personality and social psychology109, no. 3, p. 473. [doi:10.1037/pspp0000024]

DE GRAAF, N.D., P.M. De Graaf, and G. Kraaykamp. (2000). Parental Cultural Capital and Educational Attainment in the Netherlands: A Refinement of the Cultural Capital Perspective. Sociology of Education 73, no. 2: p. 92-111. [doi:10.2307/2673239]

DE RAAD, B., and H.C. Schouwenburg. (1996). Personality in learning and education: a review.European Journal of Personality 10, no. 5: p. 303-36. [doi:10.1002/(SICI)1099-0984(199612)10:5<303::AIDPER262>3.0.CO;2-2]

DIMAGGIO, P. (1982). Cultural Capital and School Success: The Impact of Status Culture Participation on the Grades of U.S. High School Students. American Sociological Review 47, no. 2: p. 189-201. [doi:10.2307/2094962]

DUMAIS, S. A. (2006). Early childhood cultural capital, parental habitus, and teachers' perceptionsPoetics 34: p. 83-107. [doi:10.1016/j.poetic.2005.09.003]

EDGERTON, J. D., \& Roberts, L. W. (2014). Cultural capital or habitus? Bourdieu and beyond in the explanation of enduring educational inequality. Theory and Research in Education, 1477878514530231. [doi:10.1177/1477878514530231]

EVANS, M. D. R., J. Kelley, J. Sikora, and D. J. Treiman. (2010). Family scholarly culture and educational success: Books and schooling in 27 nations. Research in Social Stratification and Mobility28, no. 2: p. 171-97. [doi:10.1016/j.rssm.2010.01.002]

FARKAS, G., R.P. Grobe, D. Sheehan, and Y. Shuan. (1990). Cultural Resources and School Success: Gender, Ethnicity, and Poverty Groups within an Urban School District. American Sociological Review55, no. 1: p. 127-42. [doi:10.2307/2095708]

FURNHAM, A., T. Chamorro-Premuzic, and F. McDougall. (2002). Personality, cognitive ability, and beliefs about intelligence as predictors of academic performance. Learning and Individual Differences 14, no. 1: p. 4764. [doi:10.1016/j.lindif.2003.08.002]

GOLDTHORPE, J. H. (2007). "Cultural Capital": Some Critical Observations. Sociologica, 1(2), p. 1-23.

HART, C. S. (2009). Quo Vadis? The Capability Space and New Directions for the Philosophy of Educational Research. Studies in Philosophy and Education, 28(5), p. 391-402. [doi:10.1007/s11217-009-9128-4]

HILLE, A., and J. Schupp. (2015). How learning a musical instrument affects the development of skills. Economics of Education Review44, p. 56-82. [doi:10.1016/j.econedurev.2014.10.007] 
JæGER, M.M. (2011). Does Cultural Capital Really Affect Academic Achievement? New Evidence from Combined Sibling and Panel Data. Sociology of Education 84, no. 4: p. 281-98.

[doi:10.1177/0038040711417010]

KAISER, T., and M. Diewald. (2014). Ordentliche Arbeiterkinder, konzentrierte Mittelschicht-kinder? Die ungleiche Entwicklung von Gewissenhaftigkeit im frühen Kindesalter [Tidy working-class children, Focused middle-class children? The unequal development of Conscientiousness in early childhood]. KZfSS Kölner Zeitschrift für Soziologie und Sozialpsychologie66, no. 2: p. 243-65. [doi:10.1007/s11577014-0251-z]

KOHN, M. (1989). Class and Conformity: A Study in Values 2nd ed. Chicago, IL: University of Chicago Press.

LAREAU, A., and E.B. Weininger. (2003). Cultural capital in educational research: A critical assessment.Theory and Society 32, no. 5-6: p. 567-606. [doi:10.1023/B:RYSO.0000004951.04408.b0]

MACCANN, C., A.L. Duckworth, and R.D. Roberts. (2009). Empirical identification of the major facets of Conscientiousness. Learning and Individual Differences 19, no. 4: p. 451-8. [doi:10.1016/j.lindif.2009.03.007]

MCCRAE, R.R., and P.T. Costa. (1987). Validation of the five-factor model of personality across instruments and observers. Journal of Personality and Social Psychology52, no. 1: p. 81-90. [doi:10.1037/00223514.52.1.81]

POROPAT, A.E. (2009). A Meta-Analysis of the Five-Factor Model of Personality and Academic Performance. Psychological Bulletin 135, no. 2: p. 322-38. [doi:10.1037/a0014996]

ROBERTS, B. W. (2009). Back to the Future: Personality and Assessment and Personality Development.Journal of Research in Personality 43, no. 2: p. 137-145. [doi:10.1016/j.jrp.2008.12.015]

ROBERTS, B.W., C. Lejuez, R.F. Krueger, J.M. Richards, and P.L. Hill. (2012). What Is Conscientiousness and How Can It Be Assessed? Developmental Psychology. Advance online publication. doi: 10.1037/a0031109 [doi:10.1037/a0031109]

SAVAGE, M., F. Devine, N. Cunningham, M. Taylor, Y. Li, J. Hjellbrekke, B. Le Roux, S. Friedman, and A. Miles. (2013). A New Model of Social Class: Findings from the BBC's Great British Class Survey Experiment. Sociology 47, no. 2: p. 219-50. [doi:10.1177/0038038513481128]

SCHRöDER, M., R. Siegers, and C. K. Spieß. (2013). "Familien in Deutschland" -FiD: Enhancing Research on Families in Germany. Berlin: German Institute for Economic Research.

SHANAHAN, M.J., S. Bauldry, B.W. Roberts, R. Macmillan, and R. Russo. (2014). Personality and the Reproduction of Social Class. Social Forces 93, no. 1: p. 209-40. [doi:10.1093/sf/sou050]

SULLIVAN, A. (2001). Cultural Capital and Educational Attainment.Sociology 35, no. 4: p. 893-912. [doi:10.1177/0038038501035004006]

SULLIVAN, A. (2002). Bourdieu and education: how useful is Bourdieu's theory for researchers?Netherlands Journal of Social Sciences 38, no. 2: p. 144-66.

SULLIVAN, A. (2007). Cultural capital, cultural knowledge and ability.Sociological Research Online 12, no. 6: 1. [doi:10.5153/sro.1596]

STAHL, G. (2013). Habitus Disjunctures, Reflexivity and White Working-Class Boys' Conceptions of Status in Learner and Social Identities. Sociological Research Online, 18(3). doi:10.5153/sro.2999 [doi:10.5153/sro.2999]

TRAUTWEIN, U., O. Lüdtke, I. Schnyder, and A. Niggli. (2006). Predicting homework effort: Support for a domain-specific, multilevel homework model. Journal of Educational Psychology98, no. 2: p. 438-56. [doi:10.1037/0022-0663.98.2.438]

VAN HEK, M., and G. Kraaykamp. (2013). Cultural consumption across countries: A multi-level analysis of social inequality in highbrow culture in Europe. Poetics 41: p. 323-41. [doi:10.1016/j.poetic.2013.05.001]

WAGNER, G.G., J.R. Frick, and J. Schupp. (2007). The German Socio-Economic Panel Study (SOEP): Scope, Evolution and Enhancements. In Proceedings of the 7th International Socio-Economic Panel User Conference (SOEP 2006), ed. A. Ferrer-i-Carbonell, M.M. Grabka, and M. Kroh, p. 139-70. Berlin: Duncker \& Humblot [= Schmollers Jahrbuch 127, no. 1]. [doi:10.2139/ssrn.1028709] 
WATKINS, M., \& Noble, G. (2013). Disposed to learn. Schooling, ethnicity and the scholarly habitus. London/New York: Bloomsbury Academic.

WEINERT, S., J.B. Asendorpf, A. Beelmann, H. Doil, S. Frevert, A. Lohaus, and M. Hasselhorn. (2007). Expertise zur Erfassung von psychologischen Personmerkmalen bei Kindern im Alter von fünf Jahren im Rahmen des SOEP [Collecting data for SOEP on psychological personal characteristics of five-year-old children: An expertise]. Berlin: German Institute for Economic Research. 